\title{
ANÁLISIS DE LA DAMA DUENDE Y ESCENIFICACIÓN DE NÄHTAMATU DAAM POR UGALA TEATER ${ }^{1}$
}

\author{
JAVIER J. GONZÁLEZ MARTÍNEZ \\ Universidad Internacional de La Rioja \\ javier.gonzalezmartinez@unir.net \\ JARA MARTÍNEZ VALDERAS \\ Universidad Complutense de Madrid \\ jaramart@ucm.es
}

$\Gamma$ a dama duende ha destacado dentro del repertorio del teatro clásico español por el funcionamiento de la palabra para transformar el espacio escénico en un espacio de ficción. Además ha sido un texto paradigmático para observar la construcción del espacio dramático mediante las didascalias implícitas y explícitas (González 2006). Ofrecemos ahora un estudio específico que enfoca esta peculiaridad desde la perspectiva conjunta de la filología y la escena. Este tipo de análisis, que sirve de puente entre los estudios literarios y las aplicaciones escénicas, es especialmente útil para los directores que siguen representando en la actualidad el teatro del Siglo de Oro. Así se muestra aquí, a partir del montaje de Lembit Peterson, reconocido director estonio que acaba de poner en escena Nähtamatu daam (La dama duende) en el Teatro Ugala, en la ciudad de Viljandi, que ha supuesto un hito en la tarea de situar el teatro clásico español en la escena europea.

Este artículo cumple lo que Iglesias (1998: 231) proponía para obras como esta:

Al analizar sus producciones [de Calderón] no basta con considerarlas como textos para ser leídos en la soledad del gabinete y desentrañar ahí ignotos sentidos, sino que hay que verlas y oírlas sobre el tablado o al menos levantarlas en el escenario

\footnotetext{
1 Este trabajo ha sido parcialmente financiado por el Ministerio de Economía y Competitividad dentro del Proyecto I+D Excelencia (FFI2015-65197-C3-3-P), por UNIR Research (PPI $32015-$ 2017) y por la Comunidad de Madrid y Fondo Social Europeo (S2015/HUM-3366) al Instituto del Teatro de Madrid.
}

Edad de Oro, XXXVI (2017), pp. 249-266, ISSN: 0212-042 - DOI https://doi.org/10.15366/edadoro2017.36.014 
imaginario de la mente, para contemplar su juego teatral, su verdadero funcionamiento escénico, en el que la palabra es solo un elemento más dentro de la polifonía semiótica que se despliega ante el espectador.

La propuesta escénica plasma una fiel interpretación escénica del texto dramatúrgico a partir de los medios actuales de representación. Los recursos escénicos propios de los corrales del siglo xvII que Calderón marca en su texto son sustituidos por los medios que un director tiene hoy a su alcance. Es decir, se respeta el espacio dramático y se actualiza el espacio escénico. Se responde también así a lo que afirmaba Antonucci (2006: LX): «Esta escasez de lecturas globales convincentes de nuestra comedia [La dama duende] corresponde, por lo demás, a una deficiencia propia de los estudios sobre el teatro clásico español». Y en este campo concreto encontramos un aspecto más que justifica el presente estudio: después del repaso de la bibliografía sobre esta obra calderoniana (Rodríguez 2013), es necesario recordar el significado de un término que es muy claro en dramaturgia: protagonista. A lo largo de la bibliografía se han encontrado diversas concepciones y se han presentado distintos personajes para la ejecución de las funciones del principal agonista de la obra.

Ofrecemos en este artículo un análisis dramatúrgico y una propuesta escénica. Esta además se produce en un país extranjero y de habla no hispana, en Estonia, por lo que este estudio sirve también de testimonio de la internacionalización del teatro clásico español, en general, y de La dama duende, en particular. Se suma esta escenificación a las que ha tenido la pieza en Francia, Italia, Inglaterra, Países Bajos y Alemania (Antonucci 2006: LXV).

\section{ANÁLISIS DRAMATÚRGICO}

Durante un tiempo se llegó a plantear si La dama duende era tragedia o comedia. Supuso un avance que Stroud (1977: 99) concluyese que no es tragedia. Más adelante, ya dentro de la comedia, se propuso clasificarla como comedia de enredo, pero hubo que esperar a Iglesias (1998: 216) «para evitar, por generalizador en exceso, el concepto de 'comedia de enredo'» al referirse a esta pieza. Arellano (2001: 127) matizó que pertenece al género de capa y espada, «que es el marco convencional en el que los elementos de la pieza cobran su sentido dramatúrgico». Concretamente se puede adjudicar al grupo de comedias de capa y espada «de tono acusadamente cómico» (Oleza y Antonucci 2013: 728). Pérez (2011: 19) también considera que es una comedia de capa y espada, pero añade que «el género como marco no implica convertirlo en determinante absoluto de lo que una obra puede presentar o no». Pero algo tiene que distinguir a un género de otro. Nos jugamos mucho con su definición pues, en efecto, «la noción de género dramático resulta 
importantísima para entender a Calderón» (Sánchez 2015: 8). La actual fractura en la consideración del género dramático nos distancia de la perspectiva globalizadora del teatro que se iba asentando. Ayuda considerar al género como un instrumento que define una obra. El género es así configurador del código creativo dramático, del código hermenéutico dramatúrgico, del código de concepción escénica, del código interpretativo actoral y del código de recepción espectacular. El hecho de que La dama duende sea una comedia condiciona su análisis.

Para el análisis dramatúrgico la fijación del tema es importante. El término 'tema' ha sido objeto de debate en el contexto del estudio literario a raíz de la teoría que aplicó Parker (1967) al teatro. En el campo de la dramaturgia contemporánea se entiende por tema al motivo concreto e individualizado que hace más explicable o productiva la obra teatral (Pavis 1998: 468). El tema da sentido, coherencia y unidad al conjunto de la obra. Es el punto de partida para el director y la clave de interpretación global para el espectador.

Más allá de lo que pueda parecer en una lectura rápida de La dama duende y de lo que se pueda traslucir de muchas interpretaciones, ni un ataque a la superstición ni una defensa de la mujer son el tema. En relación al primero, Arellano (2001: 135-136) anula como tema las confrontaciones superstición/racionalismo y superstición/fe, porque no cuadra con el género de comedia de capa y espada, donde no caben grandes elucubraciones filosóficas. En cuanto al segundo, Antonucci (2006: XLIV) señala que la mayor parte de las interpretaciones está viciada por anacronismos que conducen a juzgar La dama duende según su específico código cultural. En este sentido Iglesias (1998: 224-228) recopila los distintos temas que los críticos han ido apuntando para La dama duende: defensa del derecho de la mujer al amor (Honig), disconformidad de una mujer con su destino (Kuehne), búsqueda de la libertad (Mujica), defensa de la libertad de la mujer (Rey Hazas y Sevilla), la conjunción del instinto y la razón para dar sentido a la vida (Wiltrout). La anterior relación explica que Antonucci (2005: 22) afirmase: «Leyendo La dama duende con la mente libre de prejuicios, extraña el que tanta parte de la crítica no haya sabido ver lo divertida que es esta obra, y se haya empeñado en leer en ella anhelos de libertad femenina frustrados». Como se irá viendo, el estudio de la traslación del texto calderoniano a la escena y el diseño y ejecución de su escenificación ayudan a descubrir el tema y a disfrutar el humor de la pieza.

El camino que sigue la intriga nos va mostrando los logros del ingenio de doña Ángela. Este ingenio se manifiesta a través de los juegos, engaños y estrategias que despliega esta viuda para esquivar los obstáculos y alcanzar su objetivo. Doña Ángela se desenvuelve en «una sociedad menos rígida que la descrita por algunos hispanistas con morbosa delectación» (Arellano 2001: 137). La libertad es el vehículo que le va a permitir alcanzar el amor que anhela. Este amor se distingue por salvaguardar la honra y el honor (Vitse 2004: 96). Y frente a lo que pueda señalar 
algún crítico (Mujica 1980: 103), es bastante claro que el anhelo principal de doña Ángela es el amor y no la libertad. La libertad es el medio para alcanzar el fin del amor. Este desempeño de la libertad para alcanzar el amor se hace a través del juego, de la estrategia. Las acciones que ejecuta doña Ángela no son una burla, pues respeta a don Manuel, sino un juego cercano al cortejo amoroso. Y este juego no apela a la liberación de la mujer, sino que actualiza la libertad por su ejecución. En fin, el tema de La dama duende es el ejercicio de la libertad en la mujer para conseguir el amor.

Una vez fijado el tema, conviene localizar el acontecimiento que activa el conflicto de la obra, es decir, el incidente desencadenante. La dama duende ya empieza en un estado de perturbación que viene marcado por la huida de doña Ángela, por la persecución de don Luis y por la lucha entre los caballeros. Sin embargo, existe un acontecimiento que va a desequilibrar aún más el orden y va a involucrar a los personajes en el conflicto. A partir de este punto se acaba el planteamiento y comienza el nudo. Se trata concretamente del momento en que doña Ángela se percata de que don Manuel dormirá bajo su mismo techo en palabras de su hermano Luis (La dama duende, vv. 469-514; todas las citas al texto se hacen a partir de la edición de Antonucci 2006). A doña Ángela esta sorprendente noticia la espolea a agradecer el servicio que le prestó en su huida primera. A don Luis le inquieta la llegada de don Manuel a la casa por el cuidado que tiene de su hermana. A partir de este punto se fijan las metas, se localizan los obstáculos, se revelan las estrategias, se precipita el enredo, se acuerdan las alianzas con los criados. En el espectador se genera la incertidumbre y se despierta la curiosidad por saber cómo se desarrollará la acción.

El conflicto se centra principalmente entre el ejercicio de la libertad de doña Ángela y el afán de control de sus hermanos, don Juan y don Luis, que le dificultan acercarse a don Manuel. Sus hermanos representan el obstáculo mayor, aunque no el único. El hecho de que doña Ángela tenga que omitir su existencia hace que esté en todo momento preocupada por ser descubierta y tenga que pensar planes paralelos para poder llegar hasta don Manuel. El conflicto planteado entre doña Ángela y sus hermanos provoca la búsqueda de estrategias para lograr su objetivo. El conocimiento de estas estrategias permite al público participar en la comicidad de la obra, sobre todo al presentar a don Manuel y a Cosme como ignorantes de la situación.

La protagonista es doña Ángela, pues es el personaje que quiere cambiar el desarrollo de la acción. Así lo consideran también Stroud (1977: 102), Arellano (2001: 137) y Pérez (2011: 25). Doña Ángela, al verse encerrada debido al luto y las deudas, huye de casa en al menos una ocasión y por un tiempo determinado para divertirse sin que sus hermanos lo sepan. Se cruza con don Manuel, le pide ayuda, procura agradecerle el servicio prestado, le va conociendo y se enamora. 
El objetivo de doña Ángela es claro. Los antagonistas, que son la personalización del principal obstáculo, se concretan en sus hermanos. La protagonista encontrará ayudas en doña Beatriz, los criados y la alacena portátil. Doña Ángela es activa, no se queda encerrada en la casa, tiene iniciativas. Ya en su primera aparición, doña Ángela toma la iniciativa y marca el compás de la acción dramática: interrumpe el parlamento de don Manuel y le pide que estorbe la persecución de don Luis. Después de la primera aparición fugaz de doña Ángela en huida, vuelve a presentársenos más pausadamente ya en su cuarto. En este momento se fijan las circunstancias de vida de doña Ángela: vive encerrada, se queja de su «suerte cruel», de la «suerte injusta» y de la «dura estrella» (vv. 372-401). Frente a todos estos condicionantes del destino, va a aplicar su libertad. Doña Ángela está tan preocupada de no ser controlada por sus hermanos (libertad) como de cortejar a don Manuel (amor). La protagonista supera los obstáculos del cuidado de sus hermanos para tratar a don Manuel y una vez que ha llegado a él le pide ayuda para asegurar la posición frente a sus hermanos. Ha puesto los medios a través del juego de su libertad, ha llegado al fin al amor y ahora quiere asegurar la victoria. Don Manuel cumple en esta fase de la pieza la función de deus ex machina para dar fin feliz a la obra. La protagonista ha conseguido su objetivo y lo ha hecho salvando su honor. Doña Ángela se lo resume así a don Manuel: «Mi intento fue el quererte, / mi fin amarte, mi temor perderte, / mi miedo asegurarte, / mi vida obedecerte, mi alma amarte, / mi deseo servirte, / y mi llanto, en efeto, persuadirte / que mi daño repares, / que me valgas, me ayudes y me ampares» (vv. 2997-3004, versión P).

Parte de la crítica no está de acuerdo con el protagonismo de doña Ángela. Para Antonucci (2006: LV y 2017: 53) don Manuel es coprotagonista de la comedia junto con doña Ángela. La fijación del protagonista es una cuestión fundamental para el dramaturgista y para el director de actores. Su importancia no reside en que el protagonista sea uno u otro. Dependiendo de qué tema se haya fijado, cuál sea el conflicto definido, cuál la acción principal y salvaguardando la coherencia entre estos tres conceptos, el protagonista será claramente identificado. En principio, en toda obra lograda los personajes principales son siempre indispensables. Por tanto, no se trata de dilucidar quién es más indispensable, sino quién es el motor de la acción principal.

Vitse (2006: XI-XII) defiende el protagonismo de don Manuel aduciendo que

es quien abre y cierra la pieza, quien recita el mayor número de versos, quien más tiempo se queda en el escenario. Él es el personaje masculino -el señor- cuyas primera y última aparición enmarcan y determinan el curso mismo de la existencia de la deuteragonista, aquel acorralado personaje femenino - la vasalla- que se ve forzado, tanto en la escena de apertura como en la de clausura, a dirigirle una apremiante demanda de protección. 
Más adelante (Vitse 2006: XIV) continúa afirmando que don Manuel es el héroe porque tiene la iniciativa y la misión de resolver el enredo, de dar luz donde hay oscuridad, de mostrar la realidad frente a la apariencia. Sin embargo, el personaje protagonista debe ser el que se enfrente al mayor número de obstáculos. A continuación, si la cantidad de conflicto es la misma, aquel que disponga del objetivo más simpático. Finalmente, si el conflicto y la simpatía están al mismo nivel, el primero en tener un objetivo (Lavandier 2003: 65). Doña Ángela tiene más dificultades que don Manuel para alcanzar su objetivo, el objetivo de doña Ángela resulta más amable y doña Ángela es quien se anticipa al marcarse una meta. A todo esto se suma que la línea de acción de doña Ángela es distinta a la de don Manuel: una va hacia el amor y la otra hacia la verdad. La primera es la principal y la segunda es secundaria y está encaminada a la anterior. Don Manuel es dinamizador de la acción desde que descubre el primer billete y se propone averiguar qué está ocurriendo. Pero el pez no es protagonista de la pesca por morder el anzuelo y moverse: interesa que el objetivo que persigue Ángela esté vivo y coleando, pero no puede suplantarle.

A don Manuel, siendo indispensable, no se le puede considerar siquiera coprotagonista de la comedia porque quitaría relevancia a la que incluso desde un punto de vista dramatúrgico interesa que sea la única protagonista. Doña Ángela solicita ayuda a don Manuel cuando su honor está en juego y no conviene que ella dé la cara. Ella es quien se juega más en este conflicto. Ella es quien destruye el estado de cosas inicial para crear un nuevo orden. Ella es quien quiere cambiar el statu quo. Don Manuel podría ser protagonista si el tema principal fuese las confrontaciones superstición/racionalismo y superstición/fe.

Desde luego, el conflicto que se desata en La dama duende no va a ser a vida o muerte, no supone la eliminación de una de las fuerzas como si fuesen absolutamente opuestas e incompatibles. Estamos ante una comedia. Por eso, la conflictiva relación entre los hermanos «no es una relación de víctima-victimario» (Antonucci 2005: 32-33), sino que es una relación que posibilita el juego. Al mismo tiempo, necesitamos obstáculos ante los objetivos de la protagonista, por lo que sin tildarlos de crueles opresores, los hermanos, que desean otro camino para su hermana, ejercen sobre ella un excesivo control y no quieren que don Manuel descubra que habita la casa una muchacha viuda, joven y bella. Estos antagonistas son claramente personajes funcionales (García 2007: 26) que tienen más de caricatura que de personalidad (Stroud 1977: 98) y son portadores de unos códigos sociales que les hacen menos culpables y más cómicos. 


\section{Propuesta ESCÉNICA}

Vamos a abordar a continuación aspectos de la escenografía y el vestuario de la puesta en escena de La dama duende en el Teatro Ugala de Estonia, fundado en 1920. Tras tres años de remodelaciones arquitectónicas y técnicas se inauguró con este espectáculo, el catorce de marzo de 2016, la reapertura del espacio. La puesta en escena corrió a cargo de Lembit Peterson. La producción y el equipo creativo fueron al completo estonios, con excepción del diseño de escenografía y figurines (Jara Martínez Valderas y Caja Negra) y música (Germán Díaz), ambos españoles. La traducción es de August Sang (1914-1969), poeta y traductor estonio, directamente del español a su lengua materna y sin reducciones textuales.

Hemos comenzado nuestro artículo recordando que La dama duende pertenece al género de capa y espada y es, precisamente, con un signo visual en homenaje al mismo como se cerraba la representación. Para la petición de matrimonio de don Manuel a doña Ángela — que se hace con permiso de su hermano don Luis - el personaje ponía una rodilla en el suelo, se desprendía de su capa y de su espada y las colocaba en el proscenio. Este gesto tiene un doble sentido: ofrecer su mano desnuda a doña Ángela (sin capa) y abandonar el propósito de reñir con don Luis (sin espada). De esta manera, durante toda la escena final de la comedia y en los aplausos, se mantiene ese signo en el borde del proscenio como resumen del conflicto de capa y espada - conflicto de honor - que acaba de manera feliz con el desenlace del matrimonio. Para el público estonio más aventajado en el conocimiento del teatro español bien podría parecerle una metáfora de la definición de comedia de capa y espada española, y para aquellos que no conozcan tal, es simplemente una bella imagen final del fin del conflicto, donde la capa es el honor y la espada el instrumento para preservarlo. Estos signos cumplieron una función clara en la escenificación que nace del texto dramático y que un público extranjero entiende en cualquiera de sus niveles de recepción, pues la capa y la espada son elementos, como decíamos, vinculados a la acción: la defensa del honor en la trama amorosa.

Aquí radica la mayor dificultad de esta escenificación, en la recepción de un espectador ajeno a la cultura española y a nuestro teatro clásico. La siguiente dificultad - que, de la misma manera que la anterior, es una oportunidad creativa - emana del propio texto, más allá del lugar de representación, y es que el espacio escénico que plantea Calderón es consecutivo, oscilando sobre todo entre las habitaciones de doña Ángela y don Manuel. Suman siete los cambios entre estos cuartos, además de otros espacios dentro de la casa o en el exterior, como la escena en la calle que abre la obra. Los cambios entre escenas y entre jornadas deben ser rápidos, además de porque el público contemporáneo ha perdido la costumbre de largas transiciones, para no entorpecer el ritmo de la comedia. Ya 
sea en una propuesta escenográfica de una estrategia estética estilística realista $o$ abstracta (Martínez 2014: 108), el espectador debe entender el espacio en el que se hallan los personajes para captar la acción. Deben existir signos locativos, apoyados por el espacio textual emitido por los actores, porque, si no fuera así, se perdería - además de la comprensión de la trama - el efecto cómico del enredo, especialmente de la tercera jornada. Este es el primer punto de partida narrativo de cualquier propuesta escenográfica de La dama duende: la articulación de las transiciones y la clara definición del signo de los cambios espaciales entre las dos habitaciones.

Como hemos desarrollado en la primera parte de este artículo, el debate sobre el significado temático de esta obra, relacionado a su vez con la definición del protagonista de la misma, oscila entre las lecturas más inclinadas hacia la emancipación femenina y aquellas que apuestan por una lectura centrada en el honor y su relación con el amor. En la puesta en escena optaron en esta ocasión por doña Ángela como protagonista, ya que es la que demanda un cambio del statu quo haciendo que la acción avance. Es ella la que genera el conflicto principal de la obra: la oposición entre su deseo de libertad y el control social ejercido por sus hermanos. Este conflicto aparece con más pretensiones de profundidad y altura filosófica en otras obras de Calderón, pero en este caso la comedia demanda un tratamiento más ligero que permita una recepción más liviana y divertida que reflexiva, aunque el trasfondo ideológico es, evidentemente, el mismo. También don Manuel tiene un conflicto abierto entre dejarse llevar por su obligación como amigo de don Juan o su deber de amparo a doña Ángela, pero hay otro conflicto oculto que le empuja más allá del honor, que es el de la curiosidad. Quiere descubrir quién es el personaje misterioso que le escribe las cartas, pero a la vez debería desvelarle el secreto de las mismas a su amigo y anfitrión y esto supondría traicionar al primero. En este punto se sitúa cercano a doña Ángela, que también tiene como motor principal en la escenificación la curiosidad, si bien los opuestos en ella son el deber de conservar el honor y los deseos de libertad de movimientos y de relación social. La curiosidad de don Manuel es por descubrir la identidad de la mujer que escribe, quién es, y la de doña Ángela, que ya conoce la de él, es descubrir cómo es (su espacio, su ropa, su olor, su manera de expresarse, su personalidad), y es en ese descubrimiento libre del otro individuo donde aparece el amor.

El deseo de descubrimiento del mundo del otro en doña Ángela precede al de don Manuel, pues no olvidemos que Calderón sitúa al personaje en la calle, huyendo de su hermano, tapada. Este aspecto es fundamental para dar peso al argumento de la necesidad de doña Ángela de relacionarse socialmente y tener libertad de movimiento antes de la aparición del amor por don Manuel. Tener un rol social propio, ser un individuo, para que pueda suceder el amor. No podemos entender de igual manera la comedia sin este aspecto de la peripecia, pues sitúa al personaje 
femenino en rebeldía ante las imposiciones de sus hermanos. En las primeras palabras del diálogo de doña Ángela con Isabel, donde el personaje se presenta, se afirma: «Vuélveme a dar, Isabel, / esas tocas, ipena esquiva! / Vuelve a amortajarme viva / ya que mi suerte crüel / lo quiere así» (vv. 369-373) y «sin libertad he vivido, / porque enviudé de un marido, / con dos hermanos casada» (vv. 390393). Las primeras palabras del personaje son para expresar su pena por estar encerrada por sus hermanos en su habitación y su deseo de libertad. Para traducir escénicamente este cambio de situación vital de doña Ángela, de la calle (el espacio de la libertad) a la habitación (el espacio del encierro), el personaje se presentaba en su breve primera aparición pública con un vestido rojo y se tapaba el rostro y el torso con un velo de tul color verde. Al entrar en la habitación, espacio privado, la criada

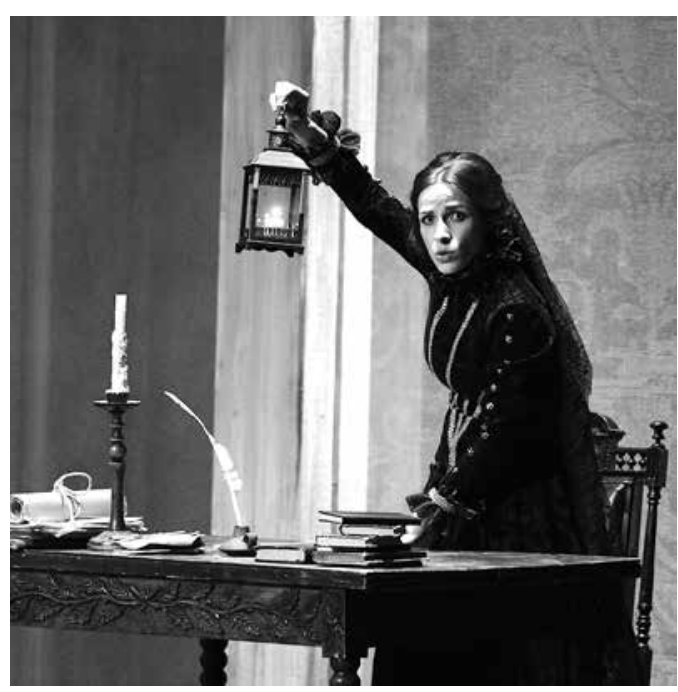

Doña Ángela y don Manuel. Fotografías de Heigo Teder.

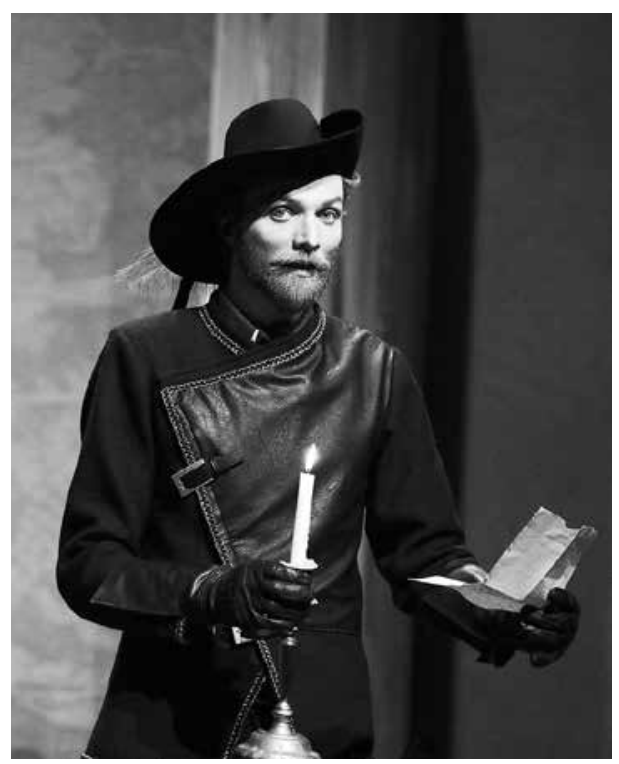

cambiaba rápidamente a doña Ángela el vestido por uno negro para disimular ante la posible aparición de sus hermanos e ir vestida de viuda. Colocaba, tal y como dice doña Ángela en el texto citado, unas tocas en su cabello. La traducción escénica era un velo de encaje negro sobre su rostro. De nuevo, la identidad del personaje femenino no puede mostrarse: primero, «tapada» en el espacio de lo público y, en su habitación, de nuevo doblemente oculta, encerrada y velada, «donde apenas el sol sabe / quién soy» (vv. 381-382). El primer velo era simple, amplio y verde, alegre; el segundo era negro y ceñido al 
rostro y, por lo tanto, daba una imagen triste del personaje. Además de la cuestión dramatúrgica, de la libertad de la calle al encierro de la habitación, la elección del verde respondía a la búsqueda de los complementarios en la rueda de color, rojo el vestido y verde el velo, que generan un tipo de armonía cromática con especial fuerza visual.
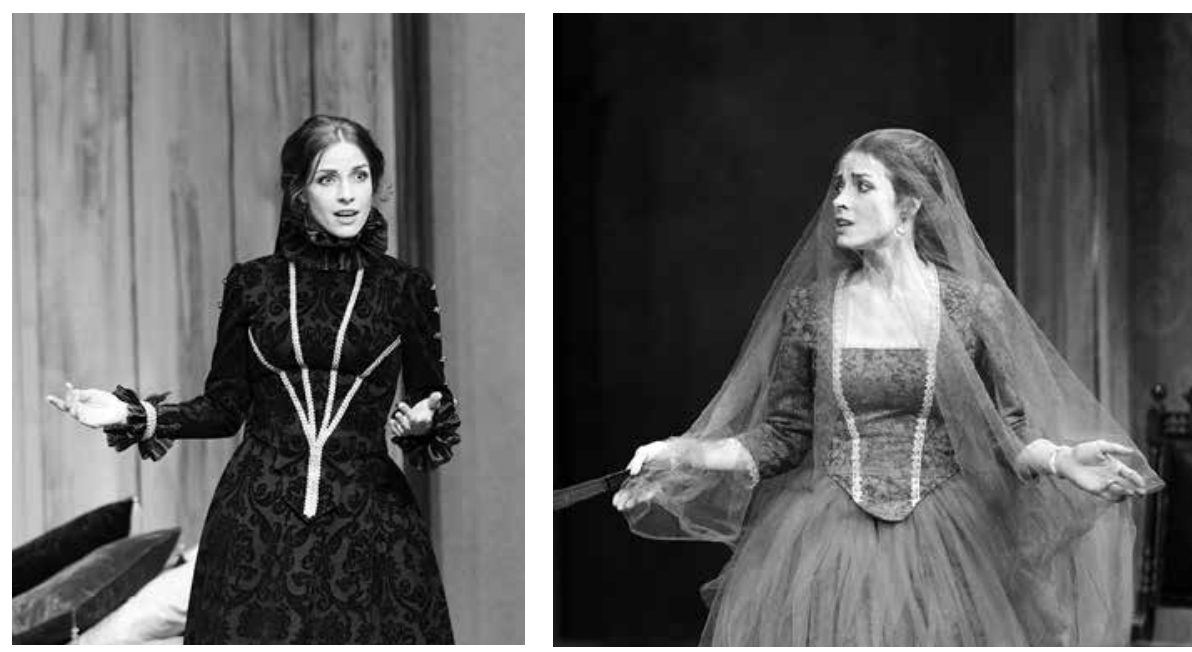

Cambios de vestuario de doña Ángela. El primero era negro y el segundo rojo y con el velo verde oscuro. Fotografías de Heigo Teder.

Esta imagen de doña Ángela al inicio y al final de la representación (cuando se descubría por primera vez ante don Manuel llevaba de nuevo el traje rojo y en la última escena de la obra volvía a ponerse el velo verde) tuvo la intención, además de caracterizar el cambio del estado de ánimo del personaje, de crear peso visual sobre la protagonista de la pieza, destacando con el rojo por encima del resto de los colores, y la de otorgarle un carácter fuerte, dinámico y atrevido. Para reforzar la idea de la libertad y del amor frente al encierro, el vestido de viuda era totalmente cerrado sobre el cuerpo y con acabados blancos en los puños y en el cuello que oprimían visualmente estas partes (idea inspirada en las gorgueras). Sin embargo, en el vestido rojo eran precisamente estas partes del cuerpo, el cuello y las muñecas, las que quedaban despojadas de tejido y mostraban la piel desnuda de la protagonista. Este cambio de vestuario conllevaba a su vez un movimiento distinto de la intérprete, que trabajaba de forma más rígida con el vestido negro y más vivaz con el rojo, incrementando esta idea de libertad en el personaje.

En esta elección de vestuario podía entreverse la lectura contemporánea y el núcleo de convicción dramática (Hormigón 2002: 157). En primer lugar la puesta en escena quería trasmitir al espectador la idea de que no hay amor sin libertad 
(los obstáculos que atraviesa doña Ángela para conseguir el amor y la libertad), $\mathrm{y}$, en segundo lugar, el espectáculo trataba de la relación entre la realidad y la ilusión. Como hipótesis de partida, para trasmitir el núcleo de convicción dramática en el diseño de escenografía, se tomó el texto del acto tercero donde doña Ángela, en un momento de sinceridad, desvela a don Manuel el misterio de la trama y de su amor: «Que yo por esta alacena / fui quien pasó cada instante / a escribirte los papeles, / a oírte, verte y visitarte, / siendo humano laberinto / con lo curioso y el arte. / Esta soy, aquesto he hecho / por quererte y estimarte; / si eres noble, por mujer / te suplico que me ampares» (vv. 3100-3109, versión V). La palabra que originó todo el diseño de escenografía es laberinto. Además de su aparición en este momento clave del texto, Antonucci (2005: 21 y 39) coincide en nombrar el laberinto como metáfora de la obra por su confusión de espacios, por jugar con las apariencias y por servir de reflejo de la sociedad. El laberinto - un camino lleno de engaños e ilusiones ficticias que conduce a una salida - podía ser una manera de expresar las dificultades de la protagonista, doña Ángela, en encontrar el amor y a su vez la libertad, ya que no son concebibles el uno sin la otra.

El diseño escenográfico respondía, entre las tres opciones posibles y no excluyentes como son el ambiente, el personaje y/o la tesis, a las tres. Si bien el espacio ayudaba al espectador a ubicarse en la España del XVII, aunque de forma estilizada y con la ayuda del vestuario, a su vez debía representar la búsqueda del amor y la libertad de doña Ángela (ambiente, personaje y tesis). El espacio y el vestuario eran emisores de significado autónomo, tal y como explicamos en estas líneas, pero se situaban como motor de la acción, y evitaban una complejidad de significado que pudiera entorpecer el género cómico, cuestión que aparece destacada en la primera parte de este artículo.

Una máxima importante de este diseño escenográfico y de vestuario es que acompañaba al arco del drama, evolucionaba con la obra dramática y con sus personajes. El laberinto debía estar desde el principio en el espacio, pero entenderse como tal en la tercera jornada. Por eso el diseño de escenografía era una estructura con un cubo central que permitía una zona oculta al espectador, y en el que se insertaba luz. Ese cubo tenía en sus cuatro caras, visibles al girar el escenario, puertas enfrentadas en dos de sus lados; una alacena que daba a la habitación de don Manuel, puerta secreta clave para el enredo; y una celosía, el único lado no practicable, que daba a la habitación de doña Ángela. Eran cuatro espacios a partir del cubo central, la habitación de doña Ángela y la de don Manuel, una a cada lado del mismo, y otros dos espacios versátiles que representaban los demás espacios de la casa, junto a una suerte de pasillos que los personajes se veían obligados a cruzar para llegar de una habitación a otra. Al girar el suelo del teatro se cambiaba con rapidez de espacio y el público podía ver a doña Ángela e Isabel cruzar estos «pasillos», introducirse en el cubo central (que ocuparía el espacio del jardín del 
espacio dramático de Calderón) y salir por la alacena. Dar visibilidad al «viaje» de doña Ángela fue una estrategia escénica. Era aquí donde ponía el acento la lectura escénica, en la valentía femenina que se arriesga a ser descubierta en el camino hacia el amor de don Manuel, poniendo en peligro su honor, que es el de la familia. Por ello, el espacio era cada vez más complejo, más laberíntico, a medida que avanzaban las jornadas (en cada cambio de las mismas se modificaban la posición de los bastidores), al igual que lo era el enredo dramático y el riesgo de la protagonista. En la primera jornada el espacio se mantenía en orden, y los corpóreos pegados a las paredes simulaban dos habitaciones de la casa; en la segunda jornada se modificaban algunas posiciones de los bastidores y simulaban pasillos; para en la tercera moverlos de nuevo y crear un laberinto.

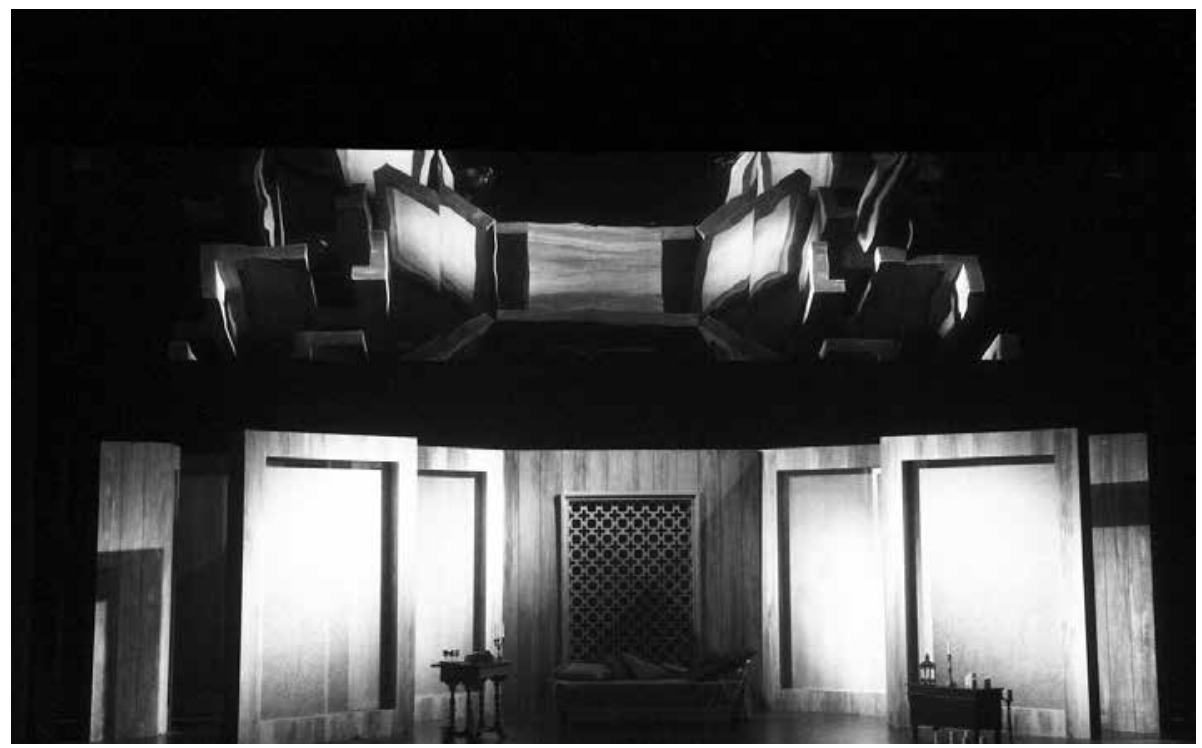

Escenografía en la tercera jornada donde puede apreciarse el espejo. Fotografía de Heigo Teder.

En el imaginario colectivo el laberinto aparecía en vista de pájaro y por eso la escenografía reforzaba este signo con un espejo de grandes dimensiones que, colocado en las varas del teatro, permanecía oculto hasta que en la tercera jornada descendía y se inclinaba sobre la escenografía, proporcionando al espectador el reflejo del laberinto sobre la cabeza de los personajes. De esta manera se afianzaba la metáfora del amor y la libertad, además de añadir un estímulo visual para evitar la monotonía y dar dinamismo a la tercera jornada. También aportaba al efecto cómico al anticipar a los espectadores la entrada de los hermanos a la habitaciones, antes de que el resto de los personajes lo supiese, lo que otorgaba al público más 
información y aumentaba la tensión de que pudieran ser descubiertos (por ejemplo, en la escena de las mujeres con Cosme).

El espejo servía también a los escritores del Siglo de Oro español como representación del mundo de las apariencias. Un ejemplo de ello lo podemos apreciar
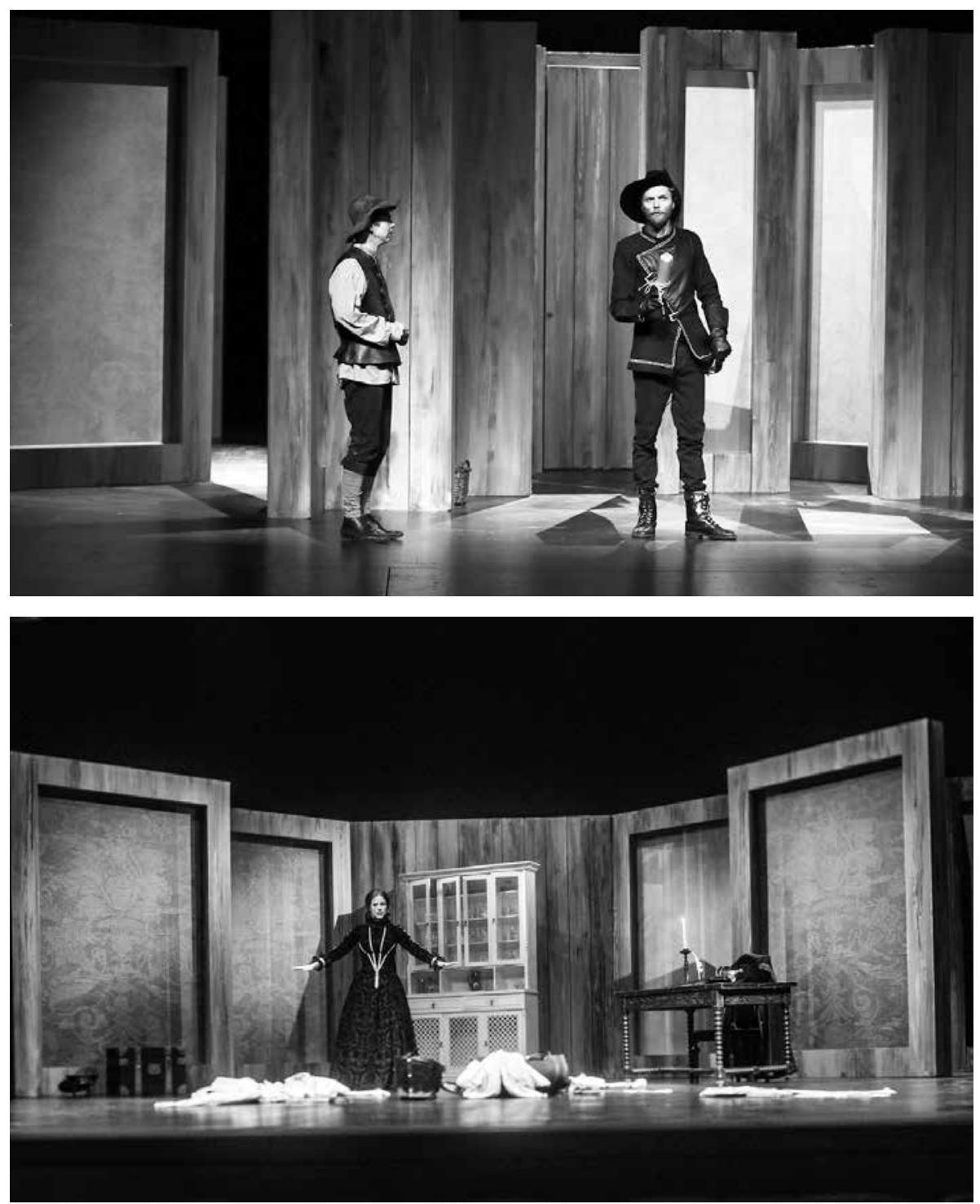

La escenografía jugaba con la luz y con las transparencias de las gasas. Fotografías de Heigo Teder. 
claramente en el personaje de Segismundo, en La vida es sueño, o en uno de los temas de La dama duende y que fue el segundo eje del diseño escénico. Cosme, el criado, entendía las apariciones físicas o en forma de carta de doña Ángela como el misterio mágico de un duende y miraba el mundo según su miedo y sus creencias supersticiosas; pero, por el contrario, don Manuel, el caballero, intentaba dar durante toda la obra una interpretación racional. Aunque no sea el tema principal, sí era tratado en la puesta en escena. De esta forma, la obra nos hablaba de dos miradas sobre la realidad, la superstición y la razón, que han sido dos caras del espejo donde el ser humano ha intentado dar explicación al mundo. En la escenificación se representaban, por lo tanto, los planos de realidad y apariencia, de razón y superstición. Para poder modificar el espacio en función de las miradas sobre la realidad de cada personaje, las gasas eran el material de los bastidores. Así la escenografía deformaba la realidad en función de los sentimientos de cada uno. Cuando don Manuel miraba y reflexionaba sobre el misterio de la dama duende, las gasas, con luz por delante, parecían paredes sólidas (recubiertas de telas que remitían a tapices de la época); sin embargo, cuando Cosme sufría el miedo de las fantasmagorías, las gasas se iluminaban por detrás, haciéndose transparentes, y el espacio se transformaba con una atmósfera que oscilaba entre lo realista y lo mágico.

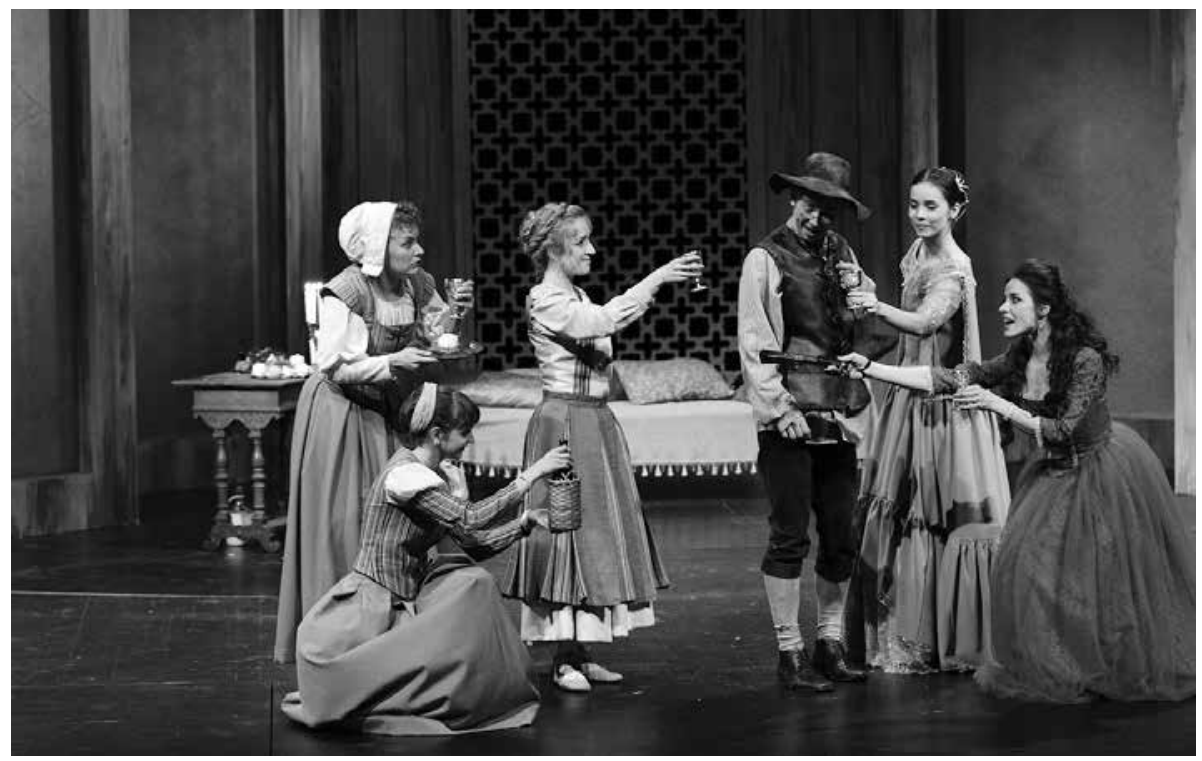

Cosme con doña Ángela, doña Beatriz y criadas. Fotografía de Heigo Teder.

Los personajes de la obra son reflejos unos de otros; don Manuel tiene su reflejo cómico en Cosme; doña Ángela, su reflejo atrevido y un tanto subversivo en Isabel; don Luis, en Rodrigo y también en don Juan, su criado y su hermano, 
respectivamente, y doña Beatriz, en Clara. El vestuario de los personajes quería trasmitir esta idea a través de los colores y las texturas. Así, doña Ángela vestía de negro y luego de rojo, los dos colores del traje de don Manuel (el rojo aparecía en los puños, el cuello y la pluma del sombrero); el criado de don Manuel, Cosme, vestía de negro; sin embargo, el criado de don Luis lo hacía de marrón, tono del traje de este personaje; Beatriz, enamorada de don Juan, llevaba un vestido azul, tono que portaba él en puños, cuello y pluma; a su vez, las otras tres criadas tenían puestos trajes más humildes, de tonalidades cálidas, que las relacionaban entre ellas visualmente.

Esta puesta en escena de La dama duende nos hablaba del triunfo del amor pero, a su vez, situaba el honor como parte indispensable del mismo, no hay amor sin honor: uno es reflejo del otro. La luz y la sombra, inspiradas en la pintura barroca, creaban una iluminación que, además de generar el sentido del tiempo oscilando entre la noche y el día, permitían que el espacio se iluminara u oscureciera al abrirse o cerrarse las puertas del cubo. Esta luz encerrada y filtrada por la escenografía generaba un efecto en el momento en el que doña Ángela declara su amor a don Manuel y este dice: «¿Qué haré en tan ciego abismo / humano laberinto de mí mismo?» (vv. 3007-3008, versión V), debatiéndose entre el honor que le empujaba a revelar el secreto a su amigo y anfitrión, don Luis, o su - ya en este punto de la trama - amor hacia doña Ángela. Justo ahora las puertas del cubo se

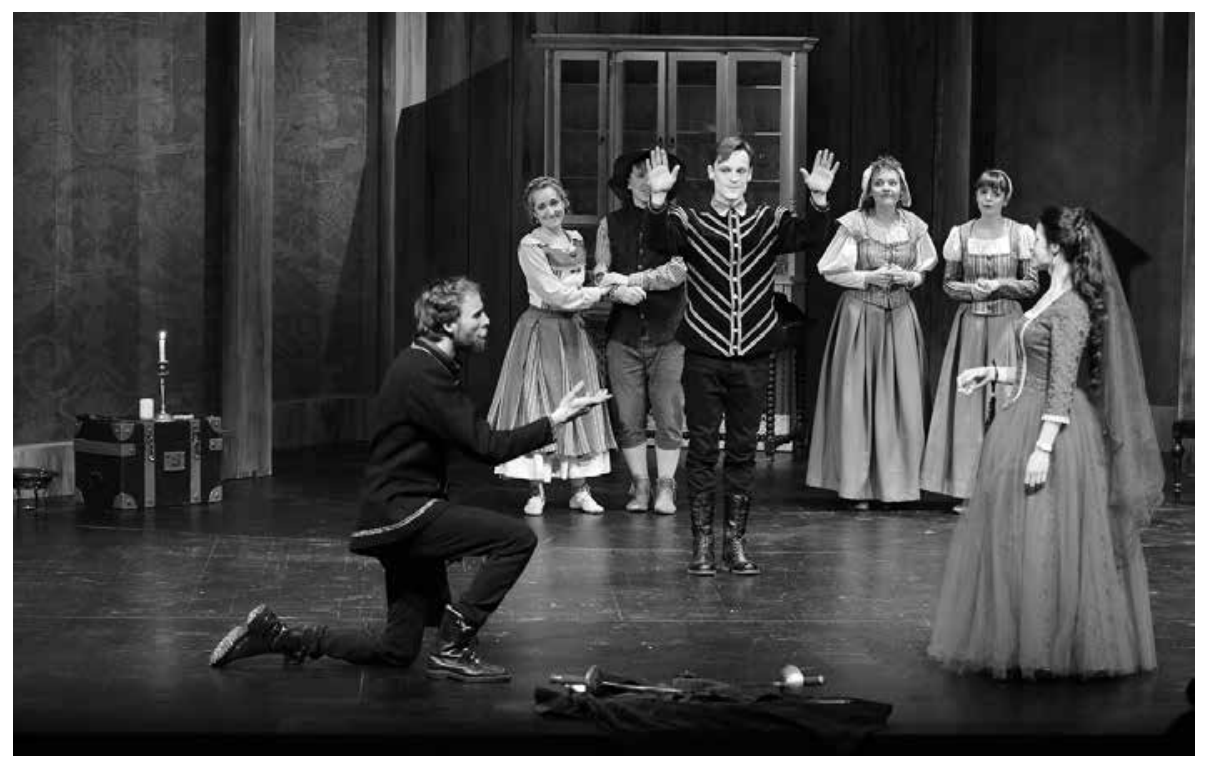

Final de la representación con la capa y la espada en proscenio. Fotografía de Heigo Teder. 
abrían lentamente y el público podía ver, a través de su reflejo en el espejo, cómo la luz inundaba el laberinto de la casa, reflejo del conflicto de los personajes.

El espacio oscilaba, como decíamos, entre el orden de la primera jornada y el progresivo desorden de la segunda y tercera para, finalmente, volver al orden al anunciar don Manuel su intención de contraer matrimonio con doña Ángela. El amor genera el orden social. En ese momento, la iluminación sobre los corpóreos desaparecía y, por lo tanto, su imagen del espejo. Ha desaparecido el obstáculo del amor, el laberinto, y el honor no se ha quebrado, podemos concluir con un final feliz la comedia, doña Ángela encuentra amor y libertad. Por lo tanto, quedaba la luz únicamente sobre los personajes en los últimos parlamentos, la escenografía detrás, a oscuras (ya no hay laberinto como no hay conflicto), y una metáfora en proscenio: el anuncio del fin de la lucha en la imagen de la espada en el suelo, y debajo la capa, como el honor que se mantiene. La imagen de un don Manuel con una rodilla en el suelo y una mano extendida hacia doña Ángela, y el permiso del hermano mayor al matrimonio, concluía con la conquista de la libertad del personaje femenino y, por lo tanto, del amor.

\section{BiBLIOGRAFÍA CITADA}

Antonucci, Fausta (2005). «Prólogo». En Pedro Calderón de la Barca, La dama duende. Fausta Antonucci (ed.). Barcelona: Crítica, pp. 7-50.

(2006). «Prólogo». En Pedro Calderón de la Barca, La dama duende. Fausta Antonucci (ed.). Barcelona: Galaxia-Gutenberg, pp. XXI-LXXv.

(2017). «Puertas cerradas y cuartos a oscuras en las tragedias calderonianas (con algunas excursiones en las comedias)». Hipogrifo, 5.1, pp. 45-55.

Arellano, Ignacio (2001). «La dama duende y sus notables casos». Cuadernos de Teatro Clásico. 15, pp. 127-139.

Calderón de la Barca, Pedro (2006). La dama duende. Fausta Antonucci (ed.). Barcelona: Galaxia-Gutenberg.

García Barrientos, José Luis (2007). «Discurso del método». En José Luis García Barrientos (director), Análisis de la Dramaturgia. Nueve obras y un método. Madrid: Fundamentos-RESAD, pp. 11-40.

GonZÁLEZ, Aurelio (2006). «De la palabra a la escena en tres comedias de Calderón». En Ignacio Arellano y Enrica Cancelliere (eds.), La dramaturgia de Calderón: técnicas y estructuras. Madrid-Frankfurt: Iberoamericana/Vervuert, pp. 229-248.

Hormigón, Juan Antonio (2002). Trabajo dramatúrgico y puesta en escena (Volumen I). Madrid: Asociación de Directores de Escena de España.

IgLeSIas FeiJoo, Luis (1998). «"Que hay mujeres tramoyeras": la "matemática perfecta" de la comedia calderoniana». En Felipe B. Pedraza y Rafael González Cañal (eds.), Actas de las XX Jornadas de teatro clásico, celebradas en Almagro, julio de 1997. Almagro: UCLM / Festival de Almagro, pp. 201-236. 
LAVANDIER, Yves (2003). La dramaturgia. Los mecanismos del relato: cine, teatro, ópera, radio, televisión, cómic. Pamplona: EIUNSA.

MARTíneZ VALDERAS, Jara (2014). «Aproximación al concepto de espacio escénico desde un planteamiento dramatúrgico». ADE Teatro, 151, pp. 106-112.

MujicA, Barbara (1980). Calderón's characters: an existential point of view. Barcelona: Puvill.

OlezA, Joan, y Antonucci, Fausta (2013). «La arquitectura de géneros en la Comedia Nueva: diversidad y transformaciones». Rilce, 29.3, pp. 689-741.

PARKer, Alexander Augustine (1967). The approach to the Spanish Drama of the Golden Age. London: The Hispanic and Luso-Brazilian Councils, Diamante Series.

Pavis, Patrice (1998). Diccionario del teatro. Barcelona: Paidós.

PÉrez Magallón, Jesús (2011). «Introducción». En Pedro Calderón de la Barca, La dama duende. Jesús Pérez Magallón (ed.). Madrid: Cátedra, pp. 11-95.

RodríGuez GALleGo, Fernando (2013). «Calderón ríe: a propósito de una nueva edición de La dama duende». Criticón, 117. <http://criticon.revues.org/247> [consulta: 13-02-2017].

SÁNCHEZ JimÉnEZ, Antonio (2015). «El género como instrumento, el género como problema». En Antonio Sánchez Jiménez (ed.), Calderón y los géneros dramáticos. Madrid: Ediciones del Orto, pp. 7-14.

STroud, Matthew D. (1977). «Social-Comic Anagnorisis in La dama duende». Bulletin of the Comediantes, 29.1, pp. 96-102.

VITSE, Marc (2004). «La comedia de capa y espada en Francia: de La dama duende de Calderón a L'esprit follet de d'Ouville». En José María Díez Borque y José Alcalá-Zamora (coords.), Congreso Internacional Proyección y significados del Teatro Clásico Español. Madrid: SEACEX, pp. 89-108.

(2006). «Estudio preliminar». En Pedro Calderón de la Barca, La dama duende. Fausta Antonucci (ed.). Barcelona: Galaxia-Gutenberg, pp. IX-XXVIII.

Recibido: $12 / 10 / 2017$

Aceptado: 25/11/2017 


\section{(2) \\ ANÁLISIS DE LA DAMA DUENDE, Y ESCENIFICACIÓN DE NÄHTAMATU DAAM POR UGALA TEATER}

RESUMEN: A partir del montaje de Lembit Peterson, director estonio, se analiza y justifica una puesta en escena de La dama duende, de Pedro Calderón de la Barca, desde la perspectiva conjunta de la filología y la escena. El objetivo es servir de puente entre los estudios literarios y las aplicaciones escénicas. Se plasma una fiel interpretación escénica del texto dramatúrgico de Calderón a partir de los medios actuales de representación, se respeta el espacio dramático y se actualiza el espacio escénico. El resultado ha sido la colaboración en la tarea de internacionalizar el teatro clásico español en la escena europea.

Palabras Clave: análisis dramatúrgico, puesta en escena, Nähtamatu Daam, La dama duende, protagonista.

\section{DRAMATURGICAL ANALYSIS OR LA DAMA DUENDE, AND SCENIC PROPOSAL FOR NÄHTAMATU DAAM BY UGALA TEATER}

Abstract: From the staging of Lembit Peterson, the Estonian director, we analyze La dama duende, by Pedro Calderón de la Barca, through the joint perspective of philology and the scene. The objective is to serve as a bridge between literary studies and scenic arts. A faithful interpretation of the dramatic text of Calderón is drawn from the present means of staging, the dramatic space is respected and the stage space is updated. The result has been the collaboration in the task of internationalizing Spanish classical theater in the European scene.

KeY WORDS: dramaturgical analysis, staging, Nähtamatu Daam, La dama duende, main character. 


\section{EDAD DE ORO}

Revista de Filología Hispánica XXXVI

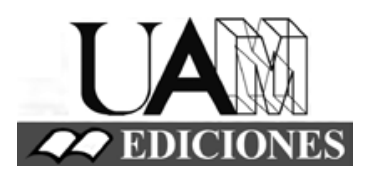




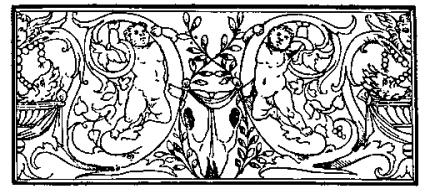

\section{Edad de Oro. Revista de Filología Hispánica}

ISSN: 0212-0429

Dirección:

Teodosio Fernández

Secretaría y edición:

José Ramón Trujillo

Consejo de redacción:

Manuel Piqueras

Blanca Santos

Admisión de originales:

María Jesús Zamora

Edad de Oro

Departamento de Filología Española

Universidad Autónoma de Madrid

28049 Madrid (España)

Tfno.: +0034914974090

correo: mariajesus.zamora@uam.es

Distribución, suscripción y venta:

Servicio de Publicaciones de la UAM

Universidad Autónoma de Madrid

28049 Madrid (España)

Intercambio de publicaciones:

Biblioteca de la Facultad de Filosofía y

Letras (UAM)

Universidad Autónoma de Madrid

28049 Madrid (España)
Comité científico internacional:

Carlos Alvar (Univ. de Ginebra)

Ignacio Arellano (Univ. de Navarra)

Javier Blasco (Univ. de Valladolid)

Alberto Blecua (UAB)

Jean Canavaggio (Univ. de París X)

Laura Dolfi (Univ. de Turín)

Aurora Egido (Univ. de Zaragoza)

Víctor García de la Concha (RAE)

Luciano García Lorenzo (CSIC)

Joaquín González Cuenca (Univ. de

Castilla-La Mancha)

Agustín de La Granja (Univ. de Granada)

Begoña López Bueno (Univ. de Sevilla)

Michel Moner (Univ. de Toulouse III)

Joan Oleza (Univ. de Valencia)

Alfonso Rey (Univ. de Santiago)

Lina Rodríguez Cacho (Univ. de Salamanca)

Leonardo Romero Tobar (Univ. de Zaragoza)

Aldo Ruffinatto (Univ. de Turín)

Lía Schwartz (City University of New York)

Han colaborado en este volumen:

Departamento de Filología Española (UAM)

Facultad de Filosofía y Letras (UAM)

Edad de Oro se recoge, entre otras, en las siguientes bases de datos: SCOPUS, MLA Database, HLAS, Latindex, PIO-Periodical Content Index, ISOC, Dialnet, MIAR, ERIH Plus, DICE, Sumaris CBUC, Ulrich's. Se encuentra evaluada en CIRC: A; MIAR difusión ICDS live 2016: 10.0; INRECH; SCImago Journal \& Country Rank: H Index 3, SJR SCImago Journal \& Country Rank 0,1, Q4; RESH índice de impacto: 0.041; ERIH: A INT1; Carhus Plus+2014: C. 